\title{
DESAIN AWAL TURBIN UAP TIPE AKSIAL UNTUK KONSEP RGTT30 BERPENDINGIN HELIUM
}

\author{
Sri Sudadiyo, Jupiter Sitorus Pane \\ PTKRN-BATAN, Kawasan Puspiptek Gedung 80, Serpong-Tangerang, 15310 \\ E-mail: sudadiyo@batan.go.id \\ Diterima editor: 14 Desember 2015 \\ Diperbaiki: 21 Juni 2016 \\ Disetujui untuk publikasi: 22 Juni 2016
}

\begin{abstract}
ABSTRAK
DESAIN AWAL TURBIN UAP TIPE AKSIAL UNTUK KONSEP RGTT30 BERPENDINGIN HELIUM. Konsep reaktor daya nuklir yang dikembangkan merupakan jenis reaktor berpendingin gas dengan temperatur tinggi (RGTT). Gas yang digunakan untuk mendinginkan teras RGTT adalah helium. Konsep RGTT ini dapat menghasilkan daya termal $30 \mathrm{MW}_{\text {th }}$ sehingga dinamakan RGTT30. Temperatur helium mampu mencapai $700{ }^{\circ} \mathrm{C}$ ketika keluar dari teras RGTT30 dan digunakan untuk memanaskan air di dalam steam generator hingga mencapai temperatur $435^{\circ} \mathrm{C}$. Steam generator dihubungkan dengan turbin uap yang dikopel dengan generator listrik untuk membangkitkan daya $7,27 \mathrm{MW}_{\mathrm{e}}$. Uap yang keluar dari turbin dilewatkan kondensor untuk mencairkan uap menjadi air. Rangkaian komponen dari steam generator, turbin, dan kondensor dinamakan sistem turbin uap. Turbin terdiri dari sudu-sudu yang dimaksudkan untuk mengubah tenaga uap kedalam tenaga mekanis berupa putaran. Efisiensi turbin merupakan parameter yang harus diperhatikan dalam sistem turbin uap ini. Tujuan dari makalah ini adalah untuk mengusulkan sudu tipe aksial dan untuk menganalisa perbaikan efisiensi turbin. Metode yang digunakan yaitu aplikasi prinsip termodinamika yang berhubungan dengan konservasi energi dan massa. Perangkat lunak Cycle-Tempo dipakai untuk mendapatkan parameter termodinamika dan untuk mensimulasikan sistem turbin uap berbasis RGTT30. Pertama, dibuat skenario dalam simulasi sistem turbin uap untuk mengetahui efisiensi dan laju aliran massa uap yang diperoleh nilai optimal $87,52 \%$ dan $8,759 \mathrm{~kg} / \mathrm{s}$ pada putaran $3000 \mathrm{rpm}$. Kemudian, turbin uap diberi sudu tipe aksial dengan diameter tip $1580 \mathrm{~mm}$ dan panjang $150 \mathrm{~mm}$. Hasil yang diperoleh adalah nilai efisiensi turbin uap naik menjadi $88,3 \%$ pada putaran konstan $(3000 \mathrm{rpm})$. Penambahan nilai efisiensi turbin sebesar $0,78 \%$ menunjukkan peningkatan kinerja RGTT30 secara keseluruhan.
\end{abstract}

Kata kunci: Tipe aksial, turbin uap, RGTT30

\section{ABSTRACT}

PRELIMINARY DESIGN ON STEAM TURBINE OF AXIAL TYPE FOR HELIUM-COOLED RGTT3O CONCEPT. The concept of a nuclear power reactor, which evolves, is high temperature gas-cooled reactor type (HTGR). Gas that is used to cool the HTGR core, is helium. The HTGR concept used in this study can yield thermal power of $30 \mathrm{MW}$ th so that named RGTT30. Helium temperature can reach $700{ }^{\circ} \mathrm{C}$ when come out from the RGTT30 core and it is used for heating the water within steam generator to achieve the temperature of $435{ }^{\circ} \mathrm{C}$. The steam generator is connected to a steam turbine, which is coupled with an electricity generator, for generating electric power of $7.27 \mathrm{MW}$. The steam that comes out from the turbine is flowed through condenser for changing the steam into water. The component train of steam generator, turbine, and condenser was given the name of steam turbine system. The turbine consists of blades that are intended to transform the steam power into mechanical power in the form of rotational speed. Turbine efficiency is a parameter that must be considered in this steam turbine system. The aims of this paper are to propose blade of axial type and to analyze the efficiency improvement of the turbine. The method used is the application of the thermodynamic principles associated with conservations of energy and mass. Cycle-Tempo software is used to obtain thermodynamic parameters and to simulate the steam turbine system based on RGTT30. Firstly, a scenario is created to model and simulate the steam turbine system for determining the efficiency and the mass flow rate of steam. The optimal values for the efficiency and the mass flow rates at the speed of $3000 \mathrm{rpm}$ are $87.52 \%$ and $8.759 \mathrm{~kg} / \mathrm{s}$, respectively. Then, the steam turbine was given the blade of axial type with a tip diameter of $1580 \mathrm{~mm}$ and a length of $150 \mathrm{~mm}$. The results obtained are turbine efficiency increasing to $88.3 \%$ on constant speed (3000 rpm). Enhancement in the turbine efficiency value of $0.78 \%$ showed raising the overall performance of RGTT30.

Keywords: Axial type, steam turbine, RGTT30 


\section{PENDAHULUAN}

Permintaan listrik di Indonesia berkembang sangat tinggi sejalan dengan pertumbuhan industri dan populasi. Hal ini dapat diatasi dengan penambahan pembangkit listrik menggunakan reaktor berpendingin gas helium dengan temperatur tinggi (RGTT). RGTT mempunyai spesifikasi antara lain bahan bakar efisien, limbah nuklir rendah, tahan terhadap penyebaran bahan nuklir berbahaya, energi tahan lama, handal, dan aman dengan adanya reactor cavity cooling system (RCCS) [1-3]. Konsep RGTT yang sedang dikembangkan saat ini diberi nama RGTT30 karena didesain dengan daya termal $30 \mathrm{MW}_{\text {th }}$ dan temperatur gas helium keluaran teras $700{ }^{\circ} \mathrm{C}$. RGTT30 diintegrasikan dengan sistem turbin uap yang merupakan rangkaian komponen dari steam generator, turbin, dan kondensor. Sistem turbin uap dikopel dengan generator listrik untuk membangkitkan daya listrik sebesar 7,27 $\mathrm{MW}_{\mathrm{e}}$. Prinsip kerja dari sistem turbin uap yang diusulkan untuk RGTT30 yaitu air dipanaskan hingga mencapai temperatur $435{ }^{\circ} \mathrm{C}$ dalam steam generator; uap yang terbentuk dilewatkan turbin yang terhubung dengan kondensor untuk merubah uap menjadi air kembali. Sistem turbin uap yang diusulkan ini didesain berdasarkan teknologi yang sudah mapan dalam proses pembangkit tenaga uap konvensional [4].

Turbin merupakan komponen kunci dari sistem turbin uap ini karena berfungsi untuk mengubah tenaga uap yang melalui sudu-sudu menjadi tenaga mekanis berupa putaran. Oleh karena itu, turbin harus didesain untuk memenuhi kondisi operasi RGTT30 pada temperatur tinggi $\left(700^{\circ} \mathrm{C}\right)$ dan tekanan 30 bar. Kedua besaran ini adalah sama dengan nilai tekanan dan nilai temperatur tinggi pada HTR-10 karena operasi terasnya telah mencapai kritikalitas $[5,6]$. Parameter yang harus dicari yaitu nilai efisiensi turbin sebagai tolok ukur dalam konsep desain ini. Semakin tinggi nilai efisiensi yang dihasilkan oleh turbin, semakin baik unjuk kerja komponen lain (termasuk steam generator dan kondensor) dalam sistem turbin uap. Pada makalah ini, diusulkan konsep turbin yang didesain dengan sudu tipe aksial agar diperoleh nilai efisiensi yang optimal. Penerapan hukum termodinamika berupa kesetimbangan energi dan massa digunakan sebagai metode dalam melakukan desain turbin ini. Penggunaan perangkat lunak Cycle-Tempo sangat membantu dalam proses iterasi perhitungan parameter termodinamika setiap komponen pada proses optimasi dari sistem turbin uap berbasis RGTT30. Simulasi pemodelan sistem turbin uap dibuat untuk memenuhi operasi teras RGTT30 pada kondisi tekanan rendah $(30$ bar $)$ dan temperatur tinggi $\left(700^{\circ} \mathrm{C}\right)$.

Dengan mempertimbangkan spesifikasi yang ada, integrasi antara sistem turbin uap dan teras RGTT30 diharapkan menjadi teknologi yang lebih kompetitif dalam pembangkitan listrik dibandingkan dengan siklus tenaga uap konvensional.

\section{TEORI}

Konsep desain RGTT30 merupakan reaktor daya berpendingin gas helium temperatur tinggi dengan daya termal $30 \mathrm{MW}_{\text {th }}$ untuk menghasilkan listrik 7,27 $\mathrm{MW}_{\mathrm{e}}$. Pembangkitan listrik berbasis RGTT30 ini mengaplikasikan sistem turbin uap yang dikopel secara langsung dengan generator listrik. Analisis dari sistem turbin uap dilakukan dengan menggunakan sebuah model siklus tak langsung dengan konfigurasi yang terdiri dari steam generator, turbin uap, dan kondensor, seperti diperlihatkan pada Gambar 1 [7]. Teras RGTT30 didinginkan dengan cara mengalirkan gas helium melalui bahan bakar nuklir berbentuk bola (pebble). Selanjutnya, helium dengan temperatur tinggi $\left(700{ }^{\circ} \mathrm{C}\right)$ dilewatkan steam generator untuk memanaskan air hingga menjadi uap pada temperatur $435^{\circ} \mathrm{C}$. Uap yang terbentuk dalam pipa-pipa siklus sekunder dari steam generator diekspansikan melalui turbin guna memperoleh kerja poros yang diperoleh dari putaran sudu-sudu dan akan dimanfaatkan untuk memutar generator listrik. Keluar turbin, uap dicairkan kembali dalam kondensor dan air kondensat dipompa kembali ke dalam steam generator. Demikian, proses berlangsung secara kontinyu.

Kondisi uap keluaran turbin beroperasi di bawah tekanan atmosfir. Uap dikondensasi dengan air dingin dalam ruang kondensor tipe shell and tube dimana kondensat mengalir dalam bagian shell. Kevakuman dalam ruang kondensor dikontrol oleh jet ejector. Turbin beroperasi pada kondisi parameter termodinamika tertentu diantaranya tekanan uap masuk, temperatur uap masuk, dan tekanan uap keluar. Hal ini akan berpengaruh pada unjuk kerja turbin yang ditunjukkan dengan nilai efisiensi 
dalam pembangkitan listrik berbasis RGTT30. Dalam siklus ideal, proses ekspansi uap melalui turbin adalah isentropik yaitu adiabatik atau tidak ada kerugian panas dimana entropi tidak berubah akibat gesekan uap melalui sudu-sudu. Oleh karena itu, nilai entropi adalah konstan walaupun nilai entalpi uap turun. Tenaga mekanis yang dihasilkan oleh turbin dan efisiensinya dapat dituliskan sebagai berikut $[7,8]$ :

$$
\begin{gathered}
\dot{W}_{T}=\dot{m}\left(h_{1}-h_{2}\right) \\
\eta_{T}=\frac{1-\frac{T_{2}}{T_{1}}}{1-\frac{T_{2 s}}{T_{1}}}
\end{gathered}
$$

dimana $\dot{W}_{T}$ adalah tenaga mekanis yang dihasilkan oleh turbin, $\dot{m}$ adalah laju aliran massa melalui sistem turbin uap, $h$ adalah entalpi uap, $T$ adalah temperatur uap yang mengalir, indeks 1 adalah kondisi termodinamika pada masukan turbin, indeks 2 adalah kondisi termodinamika pada keluaran turbin, indeks $s$ adalah proses isentropik melalui turbin, dan $\eta_{T}$ adalah nilai efisiensi turbin.

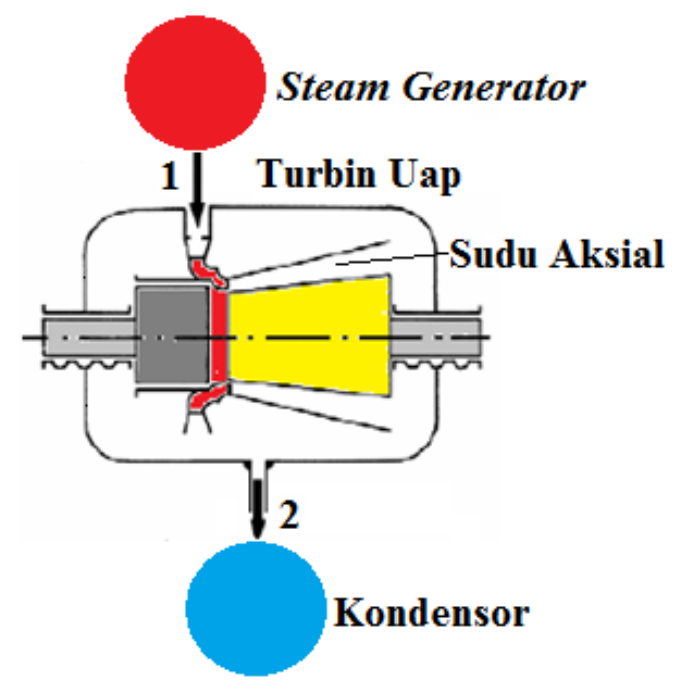

Gambar 1. Konsep dari model turbin uap [7].

Untuk mengembangkan model turbin uap tipe aksial pada RGTT30 ini diperlukan parameter tekanan, laju aliran uap, dan temperatur uap pada setiap bagian masukan dan keluaran turbin. Hubungan termodinamika untuk tekanan uap pada bagian masukan dan keluaran dari turbin didefinisikan sebagai berikut [7,9] :

$$
\dot{m}=\frac{K}{\sqrt{T_{1}}} \sqrt{P_{1}^{2}-P_{2}^{2}}
$$

dengan $P$ adalah tekanan uap dan $K$ adalah konstanta yang nilainya 520 [7]. Temperatur uap pada bagian keluaran turbin dapat dihitung dengan menggunakan formula sebagai berikut $[7,8]$ :

$$
\frac{T_{2}}{T_{1}}=\left(\frac{P_{2}}{P_{1}}\right)^{\left(\frac{k-1}{k}\right)}
$$

dimana $k$ adalah faktor ekspansi politropik. Variasi dalam nilai-nilai parameter diatas dari persamaan (1) hingga persamaan (4) akan diperoleh nilai konsumsi laju aliran massa uap dan nilai efisiensi turbin yang optimal. 


\section{METODOLOGI}

Sejalan dengan kenaikan secara kontinyu dari temperatur helium pada keadaan keluaran teras RGTT30, sistem turbin uap memberikan unjuk kerja yang baik. Oleh karena itu, nilai efisiensi turbin berbasis RGTT30 yang merupakan fungsi temperatur dianalisis dalam penelitian ini. Gambar 2 memperlihatkan konsep desain yang diusulkan dari sistem turbin uap berbasis RGTT30. Metode yang digunakan untuk melakukan analisis sistem turbin uap berbasis RGTT30 yaitu simulasi pemodelan, validasi, dan desain geometri. Simulasi pemodelan dilakukan dengan menggunakan perangkat lunak Cycle-Tempo untuk memperoleh parameter termodinamika yang sesuai dengan sistem turbin uap berbasis RGTT30. Perangkat lunak Cycle-Tempo ini mampu mensimulasikan turbin sudu tipe aksial yaitu dengan memberikan design data pada input dialog untuk turbin. Hasil perhitungan secara berulang-ulang (iterasi) dilakukan untuk mendapatkan unjuk kerja berupa nilai laju aliran massa uap melalui sudu tipe aksial dan nilai efisiensi turbin yang optimal. Validasi simulasi Cycle-Tempo dilakukan dengan memodelkan sistem turbin uap berbasis HTR-10 untuk pembangkitan listrik 2,6 $\mathrm{MW}_{\mathrm{e}}[5,6]$. Data yang diberikan dalam proses validasi yaitu temperatur dan tekanan keluaran teras RGTT30 sebesar $700{ }^{\circ} \mathrm{C}$ dan 30 bar, tekanan dan temperatur masukan turbin, temperatur keluaran turbin, dan daya listrik yang dibangkitkan. Desain geometri dari turbin uap berbasis RGTT30 dilakukan dengan metode analitis dengan menerapkan persamaan (1) sampai dengan persamaan (4). Geometri turbin didesain dengan bentuk sudu tipe aksial yang mempunyai nilai rasio diameter antara tip dan $h u b$ sebesar 0,85 [10]. Data masukan yang digunakan yaitu tekanan dan temperatur pada bagian masukan dan keluaran turbin. Data keluaran untuk memperoleh geometri turbin yaitu laju aliran massa, kecepatan uap, diameter, dan panjang sudu aksial dari turbin berbasis RGTT30 dengan media helium dan daya termal $30 \mathrm{MW}_{\text {th. }}$.

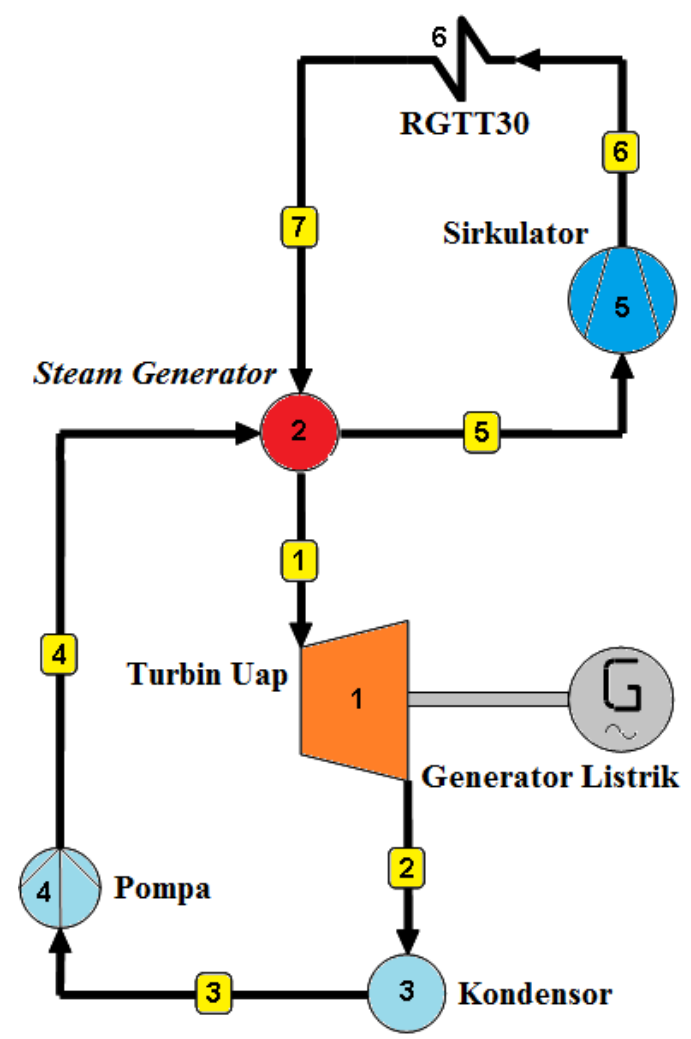

Gambar 2. Skema konsep desain sistem turbin uap berbasis RGTT30 yang diusulkan. 


\section{HASIL DAN PEMBAHASAN}

Simulasi pemodelan Cycle-Tempo dilakukan dengan memilih ikon dari setiap komponen untuk sistem turbin uap yang telah tersedia pada palet. Seperti terlihat pada Gambar 2 bahwa model konfigurasi sistem turbin uap berbasis RGTT30 terdiri dari steam generator, turbin, dan kondensor. Untuk itu dalam pemodelannya dipilih ikon-ikon yang mewakili fungsi dari komponen-komponen tersebut dan kemudian dirangkai satu sama lain sebagai pipa-pipa penghubung. Dalam penelitian ini dilakukan dua langkah kegiatan. Langkah kegiatan pertama yang dilakukan adalah membuat model tipe HTR-10 dari China guna memvalidasi simulasi model Cycle-Tempo dan selanjutnya digunakan untuk mengembangkan model sistem turbin uap berbasis RGTT30 dengan daya termal $30 \mathrm{MW}_{\text {th }}$. Table 1 memperlihatkan hasil validasi antara data termodinamika yang diperoleh dari HTR-10 China dan yang dihitung oleh Cycle-Tempo. Hasil yang dipresentasikan dalam Tabel 1 menunjukkan bahwa hasil simulasi model Cycle-Tempo adalah sangat mendekati dengan nilai operasional HTR-10 China dengan nilai penyimpangan maksimum sekitar $0,23 \%$.

Tabel 1. Perbandingan data termodinamika antara HTR-10 China dan Cycle-Tempo.

\begin{tabular}{lccc}
\hline Parameter yang diamati & HTR-10 & Cycle-Tempo & Deviasi [\%] \\
\hline Daya termal teras, $\mathrm{MW}_{\text {th }}$ & 10 & 10 & 0 \\
Daya listrik yang dibangkitkan, $\mathrm{MW}_{\mathrm{e}}$ & 2,500 & 2,503 & 0,12 \\
Tekanan masuk teras, bar & 30 & 30 & 0 \\
Temperatur masuk teras, ${ }^{\circ} \mathrm{C}$ & 250 & 250 & 0 \\
Temperatur keluar teras, ${ }^{\circ} \mathrm{C}$ & 700 & 700 & 0 \\
Laju aliran massa helium, $\mathrm{kg} / \mathrm{s}$ & 4,31 & 4,30 & 0,23 \\
Temperatur masuk turbin, ${ }^{\circ} \mathrm{C}$ & 435 & 435 & 0 \\
Laju aliran massa uap, $\mathrm{kg} / \mathrm{s}$ & 3,47 & 3,47 & 0 \\
\hline
\end{tabular}

Gambar 3 menunjukkan hasil validasi simulasi model sistem turbin uap menggunakan perangkat lunak Cycle-Tempo. Terlihat pada Gambar 3 bahwa nilai efisiensi turbin yang dihasilkan sekitar 87,48 \% untuk membangkitkan daya listrik sekitar 2,5 $\mathrm{MW}_{\mathrm{e}}$. Nilai efisensi ini terjadi akibat aliran massa uap mengalami peningkatan entropi sebesar $0,34 \mathrm{~kJ} / \mathrm{kg} / \mathrm{K}$ pada kondisi putaran turbin $3000 \mathrm{rpm}$. 


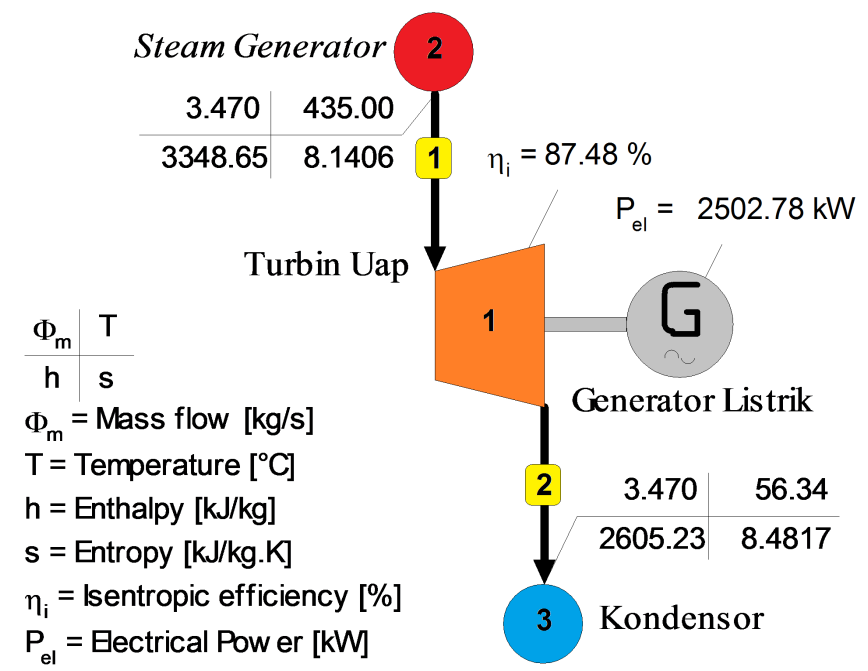

Gambar 3. Simulasi model Cycle-Tempo sistem turbin uap yang divalidasi dengan HTR-10.

Langkah kegiatan kedua yang dilakukan yaitu menggunakan hasil simulasi data aliran uap melalui sistem turbin berbasis RGTT30 berpendingin helium untuk daya termal teras $30 \mathrm{MW}_{\mathrm{th}}$. Data masukan yang diberikan dalam simulasi pemodelan ini adalah temperatur helium keluaran teras RGTT30 sebesar $700{ }^{\circ} \mathrm{C}$, temperatur uap keluaran steam generator sebesar $435{ }^{\circ} \mathrm{C}$, dan tekanan dalam ruang kondesor dipertahankan di bawah atmosfir untuk menjaga kevakumannya. Hasil simulasi pemodelan termodinamika dengan menggunakan Cycle-Tempo terhadap RGTT30 dapat dilihat pada Tabel 2 yang secara diagram dapat dilihat pada Gambar 4. Nilai efisiensi turbin ditingkatkan menjadi $87,52 \%$ pada kondisi putaran tetap $3000 \mathrm{rpm}$. Nilai laju aliran massa uap yang mengalir melalui sudu turbin adalah $8,759 \mathrm{~kg} / \mathrm{s}$ untuk menghasilkan tenaga mekanis sebesar 7,42 MW. Nilai tenaga mekanis turbin ini dikonversi menjadi daya listrik sekitar 7,27 $\mathrm{MW}_{\mathrm{e}}$ pada kondisi putaran $3000 \mathrm{rpm}$ dan nilai efisiensi generator listrik sekitar $98 \%$. Nilai temperatur uap memasuki ruang kondensor sekitar 34,91 ${ }^{\circ} \mathrm{C}$ yang masih dalam keadaan fase uap untuk selanjutnya dicairkan di dalam ruang kondensor pada tekanan di bawah atmosfir. Tipe kondensor yang digunakan adalah shell and tube terletak di bawah turbin uap dengan maksud agar aliran massa uap yang masuk kondensor tetap berada pada tekanan rendah. Dalam ruang kondensor, uap ini mengalir melalui shell sehingga akan mengalami perubahan fasa dari uap ke cairan. Air pendingin eksternal dipompakan melalui tube dalam kondensor untuk mengambil panas kondensasi uap dari turbin. Perubahan fasa sangat tergantung pada transfer panas dari uap ke air pendingin eksternal. Oleh karena itu, pembuangan panas ke lingkungan oleh air pendingin sangat penting untuk diperhatikan agar tekanan rendah dalam ruang kondensor dapat dipertahankan.

Tabel 2. Hasil perhitungan sistem turbin uap RGTT30 menggunakan Cycle-Tempo.

\begin{tabular}{lc}
\hline Parameter yang diamati & Nilai \\
\hline Daya termal teras RGTT30, $\mathrm{MW}_{\text {th }}$ & 30 \\
Daya listrik yang dibangkitkan, $\mathrm{MW}_{\mathrm{e}}$ & 7,27 \\
Tekanan masuk teras, bar & 30 \\
Temperatur masuk teras, ${ }^{\circ} \mathrm{C}$ & 250 \\
Temperatur keluar teras, ${ }^{\circ} \mathrm{C}$ & 700 \\
Temperatur masuk turbin, ${ }^{\circ} \mathrm{C}$ & 435 \\
Temperatur keluar turbin, ${ }^{\circ} \mathrm{C}$ & 34,91 \\
Laju aliran massa uap, $\mathrm{kg} / \mathrm{s}$ & 8,759 \\
\hline
\end{tabular}




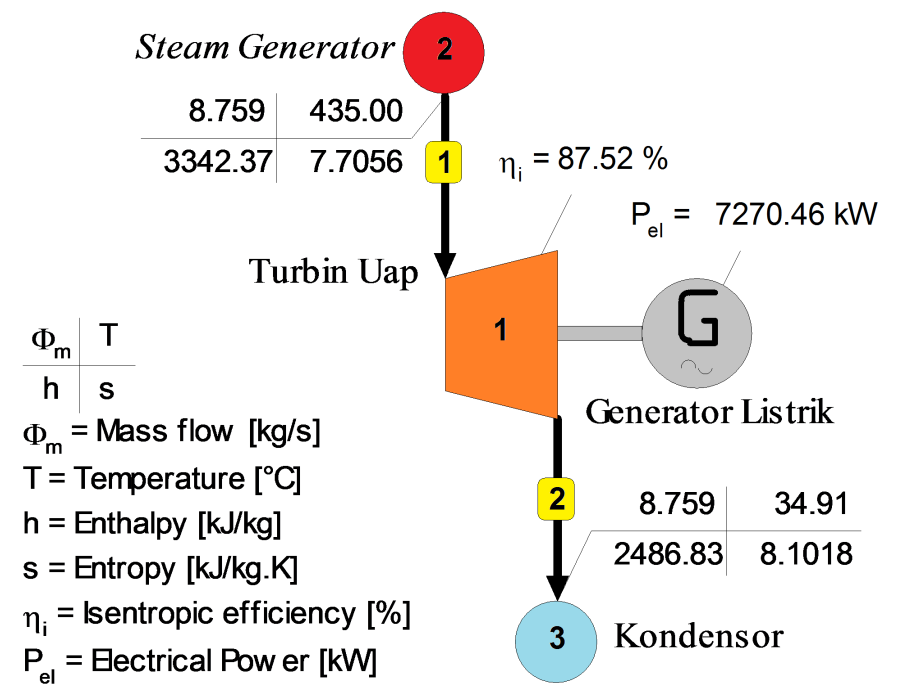

Gambar 4. Hasil simulasi sistem turbin uap berbasis RGTT30.

Gambar 5 memperlihatkan diagram tekanan kontra entalpi untuk proses sistem turbin uap pada RGTT30 yang ditunjukkan oleh garis dari titik 1 ke titik 2. Dari Gambar 5 tersebut terlihat bahwa aliran uap melalui sudu turbin berekspansi untuk memproduksi tenaga mekanis berupa putaran akibat adanya perbedaan entalpi. Dengan menggunakan persamaan (2) dan persamaan (4) diperoleh nilai rasio panas spesifik $(k)$ aliran uap dengan proses isentropik melalui turbin sebesar 1,3. Dengan menerapkan persamaan (3) dan dengan mengacu pada referensi [10] dapat didesain sudu aksial turbin uap dengan diameter tip $1580 \mathrm{~mm}$ dan panjang $150 \mathrm{~mm}$. Nilai desain geometri sudu tipe aksial ini diaplikasikan ke simulasi model dari perangkat lunak Cycle-Tempo yang telah dibuat sebelumnya (pada Gambar 4) dengan cara menambahkan data tersebut kedalam design input data geometri turbin. Hasil simulasinya diplotkan pada Gambar 6, dimana terlihat bahwa nilai efisiensi turbin yang menggunakan desain sudu tipe aksial meningkat lebih tinggi daripada nilai efisiensi turbin pada Gambar 4 dalam keadaan termodinamika sama yaitu pada temperatur uap masuk turbin $435{ }^{\circ} \mathrm{C}$ dan putaran turbin $3000 \mathrm{rpm}$. Peningkatan nilai efisiensi turbin sebesar 0,78 \% merupakan nilai kenaikkan yang signifikan dalam proses pembangkitan listrik tenaga uap. Nilai konsumsi uap juga mengalami penurunan sekitar $0,068 \mathrm{~kg} / \mathrm{s}$ yang diperhitungkan dari $8,759 \mathrm{~kg} / \mathrm{s}$ pada Gambar 4 hingga $8,691 \mathrm{~kg} / \mathrm{s}$ pada Gambar 6. Dari hasil nilai konsumsi uap ini, dapat diketahui bahwa pemakaian sudu turbin tipe aksial untuk RGTT30 berdaya termal $30 \mathrm{MW}_{\text {th }}$ akan menjadi lebih ekonomis dan kompetitif. 


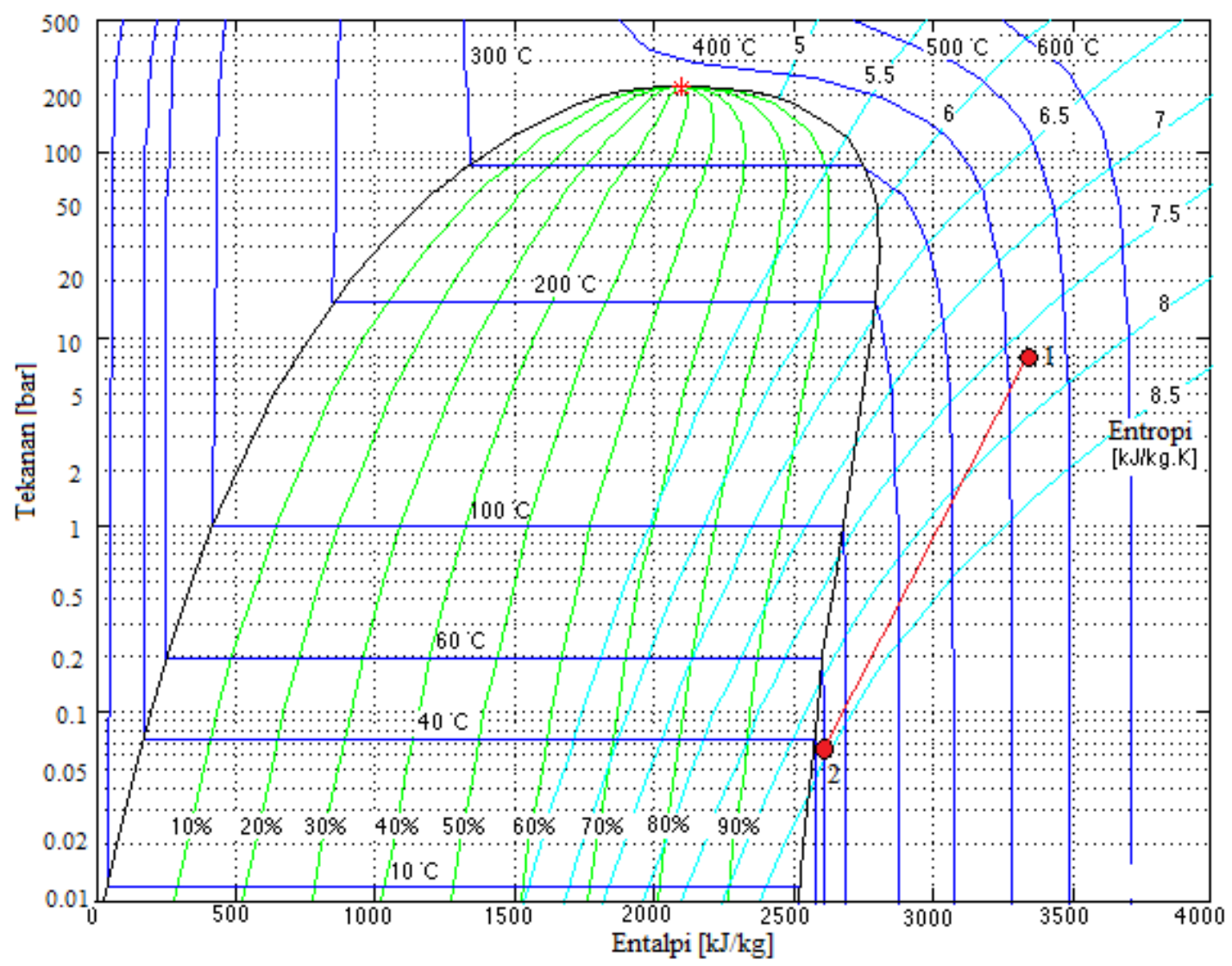

Gambar 5. Diagram tekanan terhadap entalpi dari proses turbin uap berbasis RGTT30.

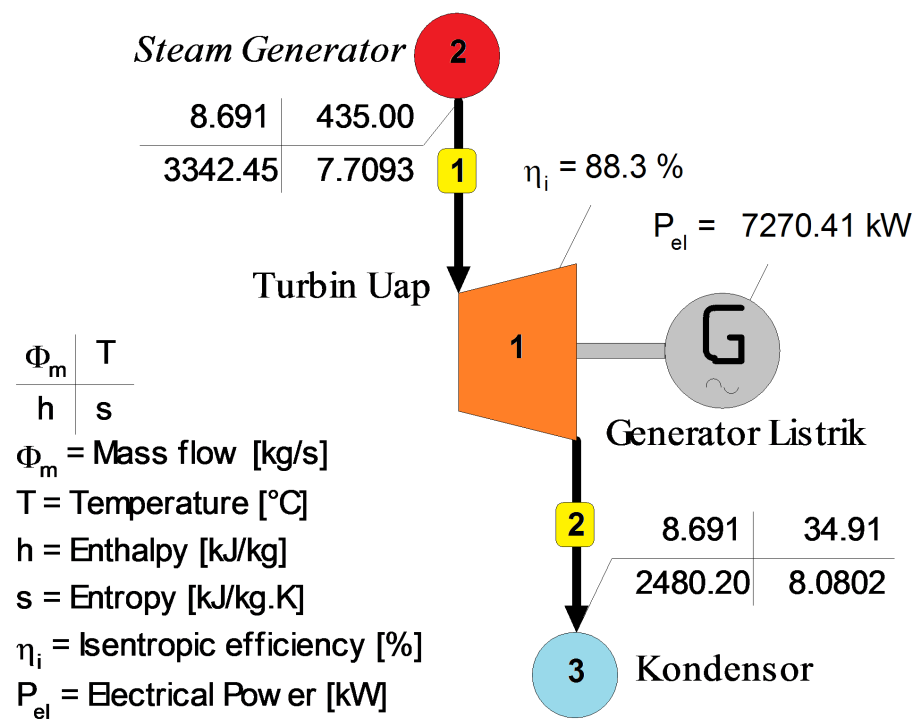

Gambar 6. Perbaikan nilai efisiensi turbin uap dengan sudu aksial berbasis RGTT30.

Dalam makalah ini, dilakukan dua skenario kasus untuk menganalisis pemodelan sistem turbin uap dengan sudu tipe aksial, menggunakan simulasi pada Gambar 6. Skenario pertama dilakukan dengan membuat daya yang dibangkitkan oleh generator listrik bervariasi dengan nilai sebesar $80 \%$ dan $70 \%$ pada kondisi termodinamika dan desain geometri sudu aksial sama. Hasilnya sebagai berikut: a). Untuk beban listrik $80 \%$ diperoleh nilai-nilai efisiensi turbin 87,9\% dan laju aliran massa uap $7,175 \mathrm{~kg} / \mathrm{s}$; b). Untuk beban listrik $70 \%$ diperoleh nilai-nilai efisiensi turbin 87,54 \% dan laju aliran massa uap $6,408 \mathrm{~kg} / \mathrm{s}$. Dari hasil kasus pertama ini dapat diketahui nilai efisiensi turbin 
diperbaiki dibandingkan dengan nilainya pada Gambar 4. Begitu juga dengan pemakaian konsumsi uapnya, didapatkan hasil yang lebih kecil dibandingkan dengan nilainya pada Gambar 4. Skenario kedua dilakukan dengan merubah nilai konsumsi laju aliran massa uap menjadi $80 \%$ dan $70 \%$ pada kondisi termodinamika dan desain geometri sudu aksial sama. Diperoleh hasil simulasi sebagai berikut : a). Untuk laju aliran massa uap $80 \%$ didapatkan nilai-nilai efisiensi turbin $87,77 \%$ dan daya listrik 5,76 $\mathrm{MW}_{\mathrm{e}}$; b). Untuk laju aliran massa uap $70 \%$ didapatkan nilai-nilai efisiensi turbin $87,41 \%$ dan daya listrik 5,01 $\mathrm{MW}_{\mathrm{e}}$. Dari hasil kasus kedua ini dapat diketahui bahwa untuk pemakaian $80 \%$ dari laju aliran massa uap diperoleh nilai efisiensi turbin naik dibandingkan dengan nilainya pada Gambar 4. Akan tetapi, untuk pemakaian $70 \%$ dari laju aliran massa uap, nilai efisiensi turbin turun $0,13 \%$ dari nilai efisiensi pada Gambar 4. Hal ini diakibatkan oleh putaran turbin dipertahankan tetap pada 3000 rpm. Jadi untuk mempertahankan efisiensi turbin, jika laju aliran massa uap diturunkan, maka putaran juga diturunkan.

Dalam proses aktual, sistem turbin uap berbasis RGTT30 dengan daya termal $30 \mathrm{MW}_{\text {th }}$ beroperasi pada kondisi yang tidak ideal. Perbaikan dari desain sudu dilakukan untuk mencapai peningkatan nilai efisiensi turbin. Dalam makalah ini, geometri sudu didesain dengan tipe aksial yang mempunyai diameter tip $1580 \mathrm{~mm}$ dan panjang $150 \mathrm{~mm}$, seperti telah disebutkan di atas. Bentuk geometri sudu turbin ini mengalirkan aliran uap kearah aksial sehingga perubahan entropi menurun yang berakibat pada kenaikan efisiensi turbin. Peningkatan entropi melalui sudu merupakan suatu kerugian energi yang dapat menurunkan nilai tenaga mekanis dari turbin. Dari Gambar 5 di atas, dapat diketahui bahwa peningkatan nilai entropi aliran uap melalui sudu turbin memberikan penurunan nilai entalpi yang kecil pada proses tekanan konstan. Penurunan beda entalpi yang kecil menghasilkan temperatur aliran uap keluaran sudu turbin menjadi lebih tinggi yang berarti nilai efisiensi turbin turun. Dengan mengaplikasikan desain awal dari geometri sudu aksial ini, hasil simulasi pemodelan dengan menggunakan Cycle-Tempo menunjukkan keuntungan dalam efisiensi turbin hingga mencapai nilai $88,3 \%$ pada putaran $3000 \mathrm{rpm}$, seperti terlihat pada Gambar 6 . Keuntungan lain yang diperoleh yaitu temperatur masuk ke ruang kondensor menjadi lebih rendah walaupun masih berwujud fase uap, seperti terlihat pada Gambar 5 di atas, sehingga kevakuman ruang kondensor dapat dipertahankan.

\section{KESIMPULAN}

Dari bahasan di atas dapat disimpulkan bahwa telah dilakukan pengembangan desain awal sudu turbin uap yang terintegrasi dengan RGTT30 berpendingin helium untuk daya termal $30 \mathrm{MWth}$. Bentuk geometri sudu didesain dengan tipe aksial yang mempunyai diameter tip $1580 \mathrm{~mm}$ dan panjang $150 \mathrm{~mm}$. Simulasi pemodelan dengan menggunakan perangkat lunak Cycle-Tempo juga telah dikembangkan untuk mengoptimasi nilai laju aliran massa uap dan untuk memperoleh nilai efisiensi turbin yang dihasilkan. Pada kondisi putaran $3000 \mathrm{rpm}$, temperatur uap masukan turbin $435^{\circ} \mathrm{C}$, dan beban listrik 7,27 MWe diperoleh nilai efisiensi turbin uap sebesar 87,52 \%. Dengan mengaplikasikan sudu turbin tipe aksial, diperoleh nilai efisiensi turbin $88,3 \%$. Terjadi perbaikan nilai efisiensi turbin sekitar 0,78 \%, dimana kedua nilai efisiensi ini dihitung dengan Cycle-Tempo.

\section{UCAPAN TERIMA KASIH}

Kegiatan Penelitian ini merupakan bagian kerja dalam Bidang Fisika dan Teknologi Reaktor (BFTR) pada Pusat Teknologi dan Keselamatan Reaktor Nuklir (PTKRN). Terima kasih kami sampaikan kepada rekan-rekan Bidang yang telah membantu dalam perbaikan makalah ini.

\section{DAFTAR PUSTAKA}

1. Nakano, M., Takada, E., Tsuji, N., Tokuhara, K., Ohashi, K., Okamoto, F., Tazawa, Y., Tachibana, Y. Core Design and Safety Analyses of $600 \mathrm{MWth}, 950^{\circ} \mathrm{C}$ High Temperature Gas-Cooled Reactor. Nuclear Engineering and Design 2014; 271:560-563. 
2. Bae, Y., Hong, S., Kim, Y. Scaling Analysis of PMR200 Reactor Cavity Cooling System. Nuclear Engineering and Design 2014; 271:523-529.

3. Capone, L., Hassan, Y.A., Vaghetto, R. Reactor Cavity Cooling System Experimental Characterization. Nuclear Engineering and Design 2011; 241:4775-4782.

4. Geete, A., Khandwawala, A.I. Thermodynamics Analysis of Thermal Power Plant with Combined Effect of Constant Inlet Pressure and Different Inlet Temperatures. Case Studies in Thermal Engineering 2013; 1:17-25.

5. Seker, V., Colak, U. HTR-10 Full Core First Criticality Analysis with MCNP. Nuclear Engineering and Design 2003; 222:263-270.

6. Xu, Y., Zuo, K., Overview of the $10 \mathrm{MW}$ High Temperature Gas Cooled Reactor. Nuclear Engineering and Design 2002; 218:13-23.

7. Chaibakhsh, A., Ghaffari, A. Steam Turbine Model. Simulation Modelling Practice and Theory 2008; 16:1145-1162.

8. Boyce, M.P. Gas Turbine Engineering Handbook. Texas: Gulf Professional Publishing; 2002.

9. Aljundi, I.H., Energy and Exergy Analysis of a Steam Power Plant. Applied Thermal Engineering 2009; 29:324-328.

10. Sudadiyo, S. Analisis Geometri Sudu Rotor Sistem Turbin-Kompresor Pada RGTT200K: Kuminarto, Nurhayati DW, Syarip, dkk, editors. PTAPB-BATAN, Prosiding PPI-PDIPTN; 29 November 2013. Yogyakarta; 2013.p. 81-86. 